\section{PREVALENCE AND INCIDENCE OF BILIARY SLUDGE AND STONES DURING PREGNANCY: A HOSPITAL BASED STUDY}

KEY WORDS: Gall Bladder, Biliary Sludge, Gall Stones, Ultrasonography.
Dr. Vikrant Gupta

Dr. Sonika Gupta* Dr. Shivani Gupta

Lecturer, Department of Radio Diagnosis, Government Medical College and Hospital, Jammu.

Consultant gynaecologist, Department of Gynaecology, District Hospital, Udhampur, Jammu. *Corresponding Author

Medical Officer, Department of Radiology, Government Hospital, Sarwal, Jammu.

OBJECTIVE: - To assess the prevalence and incidence of biliary Sludge and Stones during pregnancy.

METHODS AND MATERIAL: - The study was done on 100 healthy pregnant females. Gall Bladder ultrasounds were E- done in each trimester and 2-4weeks Postpartum.

RESULTS: - The incidence of biliary sludge and gall bladder stones during pregnancy was found to be $14.58 \%$ and $8.16 \%$ respectively. The prevalence of gall stones disease increased with advancing gestational age and it was also statistically significant $(\mathrm{p}<0.001)$. At $2-4$ weeks, postpartum gall stones have disappeared in 2 while sludge disappeared in 4. Amongst antenatal women with gall stones disease most were asymptomatic while itching was the commonest presenting symptom. A statistically significant correlation was found between gall stones disease and advanced age, high parity, prolonged breast feeding and raised BMI.

CONCLUSION: - Biliary sludge and stones develops frequently during pregnancy and are usually asymptomatic.

\section{INTRODUCTION: -}

Gall Bladder disease has a higher incidence in women than men and is particularly high in multigravida women. The patient with gall bladder disease has been classically defined as, "fair, fat, forty and fertile". Pregnancy is considered be one of the major risk factors for cholesterol cholelithiasis. Most stones contain cholesterol, and its over secretion into bile is thought to be a major risk factor in stone formation.

The incidence of gall stones disease ranges from $2.5 \%$ to $10 \%$ in pregnant women. (1) In women with preexistent gall stones pregnancy may bring out symptoms, including pain and even acute cholecystitis. In the post-partum period after gall bladder motility is restored, sludge and stones may pass from the gall bladder causing biliary colic or other complications. Alternatively, post-partum changes in bile composition may favor regression of sludge or stones. After delivery, hospitalization for gallbladder disease within a year is relatively common. Ko (2) documented that $0.5 \%$ of postpartum women were hospitalized for within a year for variety of symptoms.

Pregnant women routinely undergo real time ultrasound scanning of the pelvic area. Extension of this procedure to the upper part of the abdomen to look for gall stones in the gall bladder is easily performed and offers an opportunity for early diagnosis. A grey scale ultrasound has been shown to have a remarkable sensitivity and specificity for the detection of gall stones disease. Therefore, it is useful to evaluate the gallbladder in a group of healthy pregnant women through a series of ultrasound examination performed during the course of their pregnancy.

The present study was done with the aim to determine the prevalence and incidence of biliary sludge and gall bladder stones during pregnancy.

\section{MATERIAL AND METHODS: -}

The present study was conducted on 100 antenatal women attending the outpatient and inpatient department of obstetrics and gynecology of District Hospital, Udhampur during a period of 1 year from 2017 - 2018. It was a prospective study.

Before the performance of the ultrasound examination, all cases completed a questionnaire that sought patient demographic data and obstetric history with special emphasis on symptoms of gall bladder disease. After the obstetric ultrasound evaluation has been completed ultrasonography of upper abdomen was performed with a standard imaging protocol using a $3.5 \mathrm{MHz}$ scanning convex transverse to look for gall stones and biliary sludge.

Women were examined after fasting for at least 4 hours or having drunk few sips of water in the supine position, in the oblique position right side up, during the change from one position to another and in the standing position.

Sludge was defined as material of low echogenic activity that typically forms a layer in the most dependent portion of the gall bladder which may or may not shift with posture changes. Stones were defined as high amplitude echoes greater than $2.0 \mathrm{~mm}$ in diameter that are within the gall bladder lumen and that change with the patient's position (by gravity). Women were scheduled for an entry ultrasound during their first trimester of pregnancy. Additional, ultrasound was then scheduled during the second trimester and, or early third trimester.

Based on the findings of ultrasound cases were divided to two groups, Group I included 24 cases of gall bladder disease \& Group II included 76 cases that were found to be free of gall bladder disease. Women who developed new sludge, new stones or had progression of baseline sludge to stones were considered to have incident gall stones disease. Women with incident gall stones disease and those who were having sludge or stones at the entry ultrasound examination had follow up after delivery and an ultrasound was carried out at 2 to 4 weeks postpartum. During the study, no patient received medication to dissolve the gall bladder stones.

\section{RESULTS:-}

Table I shows the baseline data of women in the two groups. Women with gall bladder disease shows higher mean age, parity, body mass index and longer mean duration of breast feeding as compared to those who remained free of gall stones disease. 100 women were enrolled in this study during their first or second trimester of pregnancy. Biliary sludge was found in 2 and gall stones were found in 2 women at the entry examination. 22 women developed "new sludge", "new stones" or progression from baseline sludge to stones (Gall stones disease positive group) and 76 women remained free 
of gall stones disease (Gall stones disease free group). 2 cases developed new stones in the $2^{\text {nd }}$ trimester and 6 in the $3^{\text {rd }}$ trimester, 1 and 1 had progression of baseline sludge to stones in $2^{\text {nd }}$ and $3^{\text {rd }}$ trimester respectively. Hence the incidence rate for gall bladder stones was $2.08 \%$ and $6.25 \%$ in the $2^{\text {nd }}$ and $3^{\text {rd }}$ trimester respectively. The incidence of gall bladder stones and biliary sludge during pregnancy was $8.16 \%$ and $14.58 \%$ respectively. The ultra-sonographic findings of sludge and stones in antenatal women is shown in table 2 .

\section{Table 1: - Baseline Data}

\begin{tabular}{|c|c|c|}
\hline Contents & $\begin{array}{c}\text { Gall Stones } \\
\text { Disease } \\
\text { Positive (Mean) }\end{array}$ & $\begin{array}{c}\text { Gall Stones } \\
\text { Disease } \\
\text { Negative (Mean) }\end{array}$ \\
\hline Age (years) & 30.28 & 26.54 \\
\hline Parity & 2.20 & 1.15 \\
\hline $\begin{array}{c}\text { Duration of breast } \\
\text { feeding(months) in } \\
\text { those who have breast } \\
\text { fed. }\end{array}$ & 16.8 & 10.7 \\
\hline $\begin{array}{c}\text { Body Mass Index } \\
\text { (Kg/m2) }\end{array}$ & 28.4 & 24.0 \\
\hline
\end{tabular}

Table 2: - Ultra Sonography Findings

\begin{tabular}{|c|c|c|c|c|c|c|}
\hline Trimester & No. & \multicolumn{2}{|c|}{ Stones } & \multicolumn{2}{c|}{ Sludge } & Normal \\
\hline & & New & Old & New & Old & \\
\hline 1st Trimester & 100 & 00 & 02 & 00 & 02 & 96 \\
\hline 2nd Trimester & 100 & $1+1$ & 02 & 06 & 01 & 89 \\
\hline 3rd Trimester & 100 & $05+01$ & 04 & 08 & 06 & 76 \\
\hline
\end{tabular}

After delivery women were studied within 2-4weeks postpartum. Regression of sludge and stones was common. Gall stones disappeared in 2 while sludge disappeared in 4 (Table no.3).

Table 3: - Postpartum Findings

\begin{tabular}{|l|l|l|}
\hline 3rd Trimester & Ultrasound & Post-partum Ultrasound \\
\hline
\end{tabular}

\begin{tabular}{|c|c|c|c|}
\hline Sludge & 14 & Sludge Persisted & 8 \\
\hline & & Disappeared & 4 \\
\hline & & Progened to study & None \\
\hline & & Withdraw from study & 2 \\
\hline Stones & 10 & Stones Persisted & 8 \\
\hline & & Disappeared & 2 \\
\hline & & Withdraw from study & None \\
\hline
\end{tabular}

Sludge and stones were asymptomatic in most women while itching was the commonest presenting feature amongst symptomatic women. Only 1 women developed cholecystitis for which she underwent cholecystectomy in the second trimester of pregnancy. (Table No 4)

Table 4: - Presenting Symptoms.

\begin{tabular}{|c|c|c|}
\hline Symptoms & M number & Percentage (\%) \\
\hline Asymptomatic & 16 & $66.66 \%$ \\
\hline Itching & 5 & $20.83 \%$ \\
\hline Jaundice & 1 & $4.16 \%$ \\
\hline Pain in right upper quadrant & 1 & $4.16 \%$ \\
\hline Vomiting and dyspepsia & 1 & $4.16 \%$ \\
\hline More than one symptom & 1 & $4.16 \%$ \\
\hline
\end{tabular}

\section{DISCUSSION:-}

In the present study, which is based on ultrasonography done in $1^{\text {st }}$ or $2^{\text {nd }}$ trimester and finally in $3^{\text {rd }}$ trimester the formation of stones with in previously normal gall bladder or gall bladder having baseline sludge was noted in 8 women (8.16\%). Since regression of stones is relatively uncommon. This observation seems to confirm that pregnancy may pre-dispose to formation of biliary calculi. Our result was consistent with that of Bolukbas et al (3) found incident stones in $6.30 \%$ of pregnant women.

The incidence of sludge during pregnancy was $14.58 \%$ in the present series. This phenomenon may be explained on the basis of increased cholesterol saturation of bile during pregnancy and associated gall bladder hypo motility leading to cholestasis. Near similar were the observations of Giangrande et al (4) and Bolukbas et al (3) who found incidence to be $14.3 \%$ and $10.9 \%$ respectively.

The rate of disappearance of gall stones and biliary sludge was $20 \%$ and $28.57 \%$ respectively in the $1^{\text {st }}$ month after delivery. In the study of Maringhini et al (5) the rate of disappearance of stones and sludge was $28 \%$ and $68.31 \%$ respectively.

This fluctuating cause of biliary sludge and gall stone (present during pregnancy and absent after delivery) may be attributed to impressive modifications of bile and gall bladder motility that occur during pregnancy. The lithogenic bile and gall bladder stasis that is present during all of pregnancy may favor the retention of bile, nucleation and crystal formation that finally generate sludge and stones. After delivery, biliary composition and gall bladder motility return to normal. This sludge and small stones may be eliminated or dissolved as reported previously.

\section{CONCLUSION:-}

This study considered that biliary sludge develops frequently during pregnancy, is usually asymptomatic and spontaneously disappear after delivery. Gall stones may also occur with increased frequency during pregnancy.

Utilization of real time cholecystosonography adds approximately 2-5 minutes to the time required for the ultrasound procedure. The presence of gallstones could be critical to the patient's future health and may be an indication for cholecystectomy. As examination of the upper abdomen is a routine part of an intraabdominal surgical procedure similar logistics dictates that since cholecystosonography is so easily accomplished that it should become a routine addition to an obstetric ultrasound examination.

\section{REFERENCES:}

1. Maringhini A, Marceno MP, Lanzarone F, et al: Sludge and stones in gall bladder after pregnancy: prevalence and risk factors.J Hepatol 5:218, 1987.

2. KO CW: Risk factors for gall stones- related hospitalization during pregnancy and the postpartum. Am k Gastroenterol 101:2203,2006.

3. Bolukbas FF, Bolukbas C, Horizontal et al. Risk factors associated with gallstone and biliary sludge formation during pregnancy. Gastroenterology 2006;21:1150-3.

4. Giangrande M, Russo F, Coviello A, et al. Calcolie fango Della colecisti in gravida Zealand. Minerva Ginecol 1993; 45: 159-63.

5. Maringhini A, Ciambre M, Baccelliere P, et al. Biliary sludge and gallstones in pregnancy: incidence, risk factors and natural history. Ann Intern Medl 1993; $19 ; 116-20$. 